\title{
CAUSAS E ACASOS ${ }^{1}$
}

\author{
Elsa Coriat
}

[D

recisaríamos da voz e do violào de Silvio Rodriguez para cantar uma de suas cançoes. Talvez vocês a conleçam:

\section{"Cuando Pedro salió a su ventana no sabia, mi amor, no sabia, que la luz de esta clara mañana, era luz de su úllimo dia. \\ $Y$ las causas lo fueron cercando, cotidianas, invisibles, \\ y el azar se le iba enredando, poderoso, invencible." 2}

Como somos psicanalistas - e nào contamos com essa voz e com esse violào - talvez possamos reconhecer um equivalente, conceitual e estético, ao nos depararmos com essa breve frase de Freud (1973b): "O destino de um Homem é comandado por dois poderes, daimon e tyche" (p.1648).

As incompatibilidades clínicas e teóricas que estas palavras enunciam vào muito além do que podemos encontrar em uma pequena frase, perdida nas entrelinhas de sua obra. Ainda que lacan não o mencione, o enunciado freudiano aponta para as mesmas questoes que sào trabalhadas no seminário XI como automaton e tyche (Lacan, 1973, p. 60).

Em seu texto sobre o Sinistro, diz Freud (1973c): "Limito-me, pois, a indicar que a ativiclade psíquica inconsciente é dominada por um automatismo ou impulso de repetiçào (repetição compulsiva) $[. .$.$] provido de poder sufi-$ ciente para se sobrepor ao princípio de prazer; um impulso que confere a certas manifestaçoes da vida psíquica um caráter demoníaco (...)" (p. 2496).

O demoníaco, entào, compulsão à repetição, rede significante funcionanclo como automaton, por um lado, e, por outro, tyche, o acaso, o encontro como real, ambos poderes comandando o destino de cada homem em particular.

Ao atualizar estas conceituaçoes, procuro apresentar um enquadre adequado para elaborar um texto no qual me proponho a trabalhar a seguinte questão: Que causas determinam a apariçào, no real, de uma psicose infantil?

Psicanalista; membro da Escuela Freudiana de Buenos Aires, membro da equipe de direção do Centro Dra. Lydia Coriat de Buenos Aires, Argentina. 
Se, em Posiçào do Inconsciente, lacan (1985a) diz que "o efeito de linguagem é a causa introduzida no sujeito, e que graças a esse efeito nào é causa de si mesmo, traz em si o cerne da causa que o cincle, pois sua causa é o significante sem o qual nào haveria nenhum sujeito no real" (p. 814); e se nas psicoses infantis justamente o que nào aparece no real é esse sujeito cindido, sujeito à legalidade que impòe o estabelecimento da repressào do inconsciente; seriam suficientes as causas localizadas no campo onde operam os efeitos do significante - incluindo aqui tanto o imaginário como o real da repetiçào e do ato - para dar conta do porquê da apariçào de uma psicose infantil?

Falando em termos mais simples, volto a abrir o velho debate: A causa da psicose infantil é orgânica ou psicológica (ou, em termos mais atuais, orgânica ou significante)?

Quando comecei a trabalhar no campo dos problemas do desenvolvimento infantil, minhas articulaçoes teóricas e minha correspondente leitura dos materiais clínicos visavam esclarecer um preconceito enormemente difundido, que preconizava que determinados quadros genéticos ou neurológicos comportavam em si determinadas características psicopatológicas, incluindo entre elas psicose e autismo.

Tomando muitas vezes como paradigma a Síndrome de Down - dada a elevada freqüência estatística de sua apresentaçào - pude ir situando os caminhos em que se favorecia a produçào de uma criança desconectada ou psicótica, justamente onde o genético não impedia em absoluto que aparecesse um sujeito do desejo.

Mas nào só de Síndrome de Down está feito o campo dos problemas do desenvolvimento: quem desta vez traz novamente à tona a pergunta é um setor da populaçào infantil de aparência física normal, sem um diagnóstico médico definido que vá além de "retardo de maturaçào" ou "imaturidade psicomotora" (ou alguma outra imprecisào semelhante); crianças que foram submetidas a todos os estudos com os qua is conta a medicina moderna até a presente data, sem que nenhuma alteraçào se revelasse nestes, e, apesar disso, são decididamente psicóticas (ou autistas).

Escutando os pais de algumas destas crianças, aparentemente normais no aspecto físico, podemos chegar à convicçào de que, se a criança é psicótica, é porque isso vinha se preparando descle uma história prévia, como se fosse se modelando no real o objeto fantasmático necessário às coordenadas significantes do par parental. Mas com outros... Acontece que com outros... as coisas não se encaixam; quero dizer que, escutando os pais destes outros, nào encontramos razòes suficientes, no discurso, para que tenha aparecido uma psicose na criança.

O lugar de pai (ou de màe) é, por estrutura, um lugar fracassado; mas essa falha, em geral, toma o caminho de uma neurose na criança. Seria necessário um plus, seja na quantidade ou na qualidade da falla, para que se produzisse uma psicose ou um 
autismo. E se esse plus não se encontra no discurso, é lícito supor que a causa advenha de outro lugar.

Nossa pergunta se vê reforçada quando levamos em conta outros tipos de materiais clínicos; refiro-me aos casos nos quais nos fazemos uma pergunta que é quase a inversa, qual seja: como se virou determinada criança para nào se tornar psicótica, dadas as condiçòes nas quais foi criada?

Observamos que algumas vezes é muito difícil produzir um psicótico ou um autista, e que outras vezes, é extremamente fácil. O que faz a diferença?

A frase de Freud que citei anteriormente, está situada numa nota de rodapé de "A Dinâmica da Transferência", no centro de um parágrafo que não pode ser desperdiçado. Se vamos nos perguntar sobre a causa, convém levar em conta suas primeiras entrelinhas. Começa assim: "Pelo fato de ressaltarmos a importância das marcas infantis, acusam-nos de negar a que corresponde aos fatores congênitos (constitucionais). Esta crítica tem sua origem na restrita necessidade causal do homem, que, em franca contradiçà com a estrutura geral da realidade, procura satisfazer-se com um único fator causal". (Freud, 1973b, p. 1648)

Nào damos conta da realidade da clínica de crianças, da leitura do real que ali está em jogo, com um único fator causal. A eficácia da causa significante vem sendo muitas vezes comprovada na estruturação de uma psicose; mas também a remissão de alguns casos tem sido possível graças à administracào de determinada medicação específica, comprovando-se ali a incidencia do orgânico .

Freud (1973b) continua, dizendo: "Recusamo-nos a estabelecer uma oposiçào fundamental entre ambas séries de fatores etiológicos", o qual me pare- ce coerente nào apenas com a realidade da clínica mas também com as seguintes palavras de Lacan (1986): "Nào afirmamos que a psicose tem a mesma etiologia que a neurose, tampouco afirmamos que da mesma forma que a neurose, é uma pura e simples açào de linguagem" (p. 91).

Voltemos a Freud (1973b), que afirma: "A psicanálise disse muitas coisas sobre os fatores acidentais da etiologia e muito pouco sobre os constitucionais, mas somente porque podia contribuir para os primeiros com grande quantidade de novos dados e, em troca, nào sabia nada especial sobre os últimos, exceto o já conhecido".

Sobre os fatores constitucionais enquanto anatomia e fisiologia do organismo biológico que é cada corpo humano - passado quase um século do comentário freudiano, a psicanálise pode acrescentar muito pouco, mas não se pode dizer o mesmo da neurologia e ciências afins.

Com os avanços em matéria de métodos diagnósticos, tanto nos estudos por imagens, como neurometabólicos ou genéticos, uma considerável proporçào das crianças autistas ou psicóticas que até 5 ou 10 anos atrás eram consideradas organicamente "normais", deixaram de sê-lo.

Estamos em um tempo no qual a cada mês sào descobertas novas peças no quebra-cabeças do genoma humano, novas substâncias cuja presença no organismo é condiçâo para que possa funcionar o equipamento cerebral, novos métodos para ter acesso visual à localizaçào da mais mínima matéria lesada ou mal-situada ou com um funcionamento alterado. A cada nova descoberta, vai se reduzindo a populaçào de crianças psicóticas sem um diagnóstico neurológico específico. Ao mesmo tempo, entre as crianças psicóticas é altíssima - e cada vez maior - a descober- 
ta de alguma carência, falha ou dano orgânico no cérebro.

A partir da psicanálise, haverá também algo novo com o que possamos contribuir?

Baseando-nos na experiência clínica recolhida no campo dos problemas do desenvolvimento infantil, e na leitura daquilo que neste campo encontramos, a partir das teorizações de Freud e Lacan, talvez possamos propor uma conceituaçào sobre as causas que intervêem na etiologia das psicoses e do autismo infantil, que supere a velha e célebre antinomia.

Entre as duas facçoes rivais - organicistas e psicologicistas (incluindo aqui um bom número de psicanalistas) - em mais de uma ocasiào houve uma trégua, reconhecendo a importância de ambos fatores, mas sem saber de que maneira o que occorre no campo da disciplina vizinha incicle sobre o próprio.

Diz Freud (1973b): "A série formada pelas combinações de ambos fatores em diferentes magnitudes deve ter seus casos extremos". Não se trata, então, de uma adiçào de causas ou fatores, mas de uma combinatória. Procuraremos avançar, especificamente, sobre a maneira de se tecer está combinatória, para dar como resultado, em vez da delicada trama de um inconsciente neurótico, o extenso nó da psicose.

Em "Projeto de uma Neurologia para Psicanalistas" - apresentado ná Reunião Lacanoamericana de Porto Alegre - eu propunha e fundamentava uma metáfora na qual considerava o sistema nervoso central como o papel no qual o Outro inscrevia as letras fundantes, ou seja, as marcas, os traços, os $\$ 1$ constitutivos do primeiro tempo de alienaçào, e dizia: "A neurologia se ocupa do papel, a psicanálise do que fica escrito".(Coriat, 1997).

Em "As Psicoses e as Crianças" trabalho apresentado na Reuniào Laca- noamericana de Buenos Aires - definia as psicoses infantis em função da não inscriçào do significante do Nome-doPai, fazendo depender essa inscrição das sucessivas reinscrições da experiência de separação em cada um dos tempos da primeira infância.

Pois bem, para que algo fique escrito, nào é suficiente somente o desejo posto em jogo através da mão que escreve o texto, também é preciso um papel ou equivalente (qualquer substância material) no qual o traço possa ficar registrado.

Quando escrevemos, em geral nos esquecemos do papel, atentos somente às palavras que queremos deixar ali; mas necessariamente passamos a leválo em conta quando alguma das características materiais do papel dificultam que as letras sejam escritas com clareza.

Todo bebê nasce imerso em um banho de linguagem. Esta cacofonia significante - insignificante para o bebê em seus primeiros tempos quanto a seu sentido - chega ao bebê filtrada pelo Outro real, encarnado na pessoa que exerce funçào materna, quem vai escrevendo as primeiras letras em seu corpo, a partir de cada ato cotidiano, com o que possibilita o percurso de sua vida de bebê. Caderno maravilhoso que permite, de uma ou outra maneira, que o arquivo fique registrado no sistema nervoso central.

Os pais normais escrevem sobre os bebês que nascem normais sem prestar maior atençào. Uma mãe pode nào lembrar em que momento seu bebê disse "agá" pela primeira vez, ou sustentou a cabeça, ou se sentou, ou pegou um chocalho, ou ficou em pé agarrado às grades do berço; pode nem sequer saber se passou ou nào pela angústia dos dezoito meses, mas se seu bebê pôde passar por cada uma de semelhantes transformações foi porque ela, sem sabê-lo, sabia que tipo de sus- 
tentaçào ou de objeto, diferente a cada dia, requeria a criaçào de seu filho.

As açòes que envolvem a funçào materna são exercidas a partir do saber do Outro, mas cada ato é convocado a realizar-se em função daquilo que cada mãe possa ler em cada momento em seu bebê: se quer comer ou dormir, se quer mimos ou troca de fraldas. A leitura materna se faz a partir de sua própria história significante, a partir de seu gozo e de seu desejo, mas se faz sobre os indicios que pode ir recolhendo em seu bebê, a partir da maneira em que este responde a seus cuidados ou descui-

dos. Desta forma, vai se escrevendo o primeiro sistema de marcas, o dos signos perceptivos, transcrição das percepcòes, da qual fala Freud (1973a) em "Carta 52". Assim que este sistema começa a construir-se - e isso ocorre inevitavelmente desde a primeira experiência do bebê - o escrito pelo Outro penetra na dotaçào de reflexos biologicamente herdados, passando a ordenar as condutas do bebê em função do vivido como prazer ou desprazer.

Se para essa màe, na relação com stu bebê, opera a Lei fundante da cultura, o sistema de marcas que ali se inscreva implicará uma ordem, uma determinada e singular concatenaçào, que lhe permitirá, em seu tempo e em função das novas experiências do bebê, ir construindo o segundo sistema de transcriçoes, o inconsciente, e, posteriormente, o terceiro.

Dizia também em meu "Projeto" que, nos primeiros tempos, o que está em jogo nas experiências com o outro nào é somente a inscriçào dos primeiros sinais mnêmicos, mas também o estabelecimento das Babnung, facilitação ou estabilizaçào seletiva das sinapses neuronais. $O$ significante intervém então nos últimos passos da construção biológica de um cérebro que nasceu imaturo, não somente psíquica mas também neurologicamente.

A partir da "Carta 52", as metáforas da psicanálise supòem um papel que, sem dificuldades e de maneira semelhante, possibilita as inscriçoes operadas pela mão do Outro. Se o papel fosse igual em todos os casos, as diferenças pessoais passariam exclusivamente pela singularidade do desejo dos pais, pelo lugar do fantasma a partir do qual cada criança é imaginada e manipulada, esperada e encontrada.

Mas nào existem dois papéis-cérebro iguais, nem existem dois bebês que, a partir de sua bagagem congênita, respondam da mesma forma à demanda do Outro. Nestes tempos, outorgar um lugar prínceps à diferença deixou de ser atributo exclusivo da psicanálise, as neurociências dào conta disso a cada passo. E a construçào do papel-cérebro, da concepçào ao nascimento, requer tal quantidade de operaçòes de ordens as mais diversas, que, no caminho, pode acontecer todo tipo de acidentes - acidentes biológicos que impeçam a realizaçào de algumas das funções que the competem. Pode ocorrer que esta falha nào seja eliminada de maneira espontânea, nem sequer levando-se em conta a maravilhosa plasticidade neuronal.

De tudo isso, então, observamos que os casos extremos da série de combinaçoes que dariam como resultado uma psicose infantil seriam: em um extremo, um papel biologicamente impecável que é recebido a partir de um lugar perverso, de objeto de gozo no real; e, em outro extremo, um papel seriamente afetado em sua possibilidade de converter-se em depositário de uma série de marcas ordenadas a partir do significante do Nome-do-Pai, por cuja razào a criança se tornará psicótica (ao menos durante algum tempo de sua infância) por mais que ocupe um lugar 
no qual, do lado dos pais e na relaçào com seu filho, opere a lei.

Entre um extremo e outro da série, estao todas as combinaçoes possiveis que é o que ocorre na devastadora maioria dos casos.

Às vezes nos deparamos com pais onde tudo nos leva a supor que, se seu bebê tivesse nascido orgânicamente normal, este se haveria convertido $\mathrm{cm}$ uma criança neurótica qualquer, sem maiores complicaçoes que sua própria singularidade; mas receberam um filho que, ao ser portador de uma falha detectável, feriu seu narcisismo de tal forma que nào foi possivel que o pequeno bebê recebesse a série de inscriçoes que previamente lhe estava destinada.

Outras vezes, o que recebem é um filho sem nenhuma falha rapidamente detectável, mas cuja dotação biológica não oferece as respostas que, normalmente, realimentam o chamado do Outro, provocando uma série de desencontros entre mãe e fillho que são percebidos somente muito mais tarde, quando as produções da criança não atingem o esperado em sua idade ou fazem-no de maneira muito pouco usual.

A psicanálise nào perde nada reconhecendo o peso causal dos fatores orgânicos: na clínica das psicoses infantis, o decisivo é sustentar o desejo e as marcas que correspondem a ele. Quando o papel nào responde imediatamente, nào se trata nem de abandonar o traço nem de passar a escrever outra coisa - que é o que sistematicamente orienta fazer o condutismo, em todas as suas recentes versòes.

Um pai que veio consultar-me depois de ter passado por um bombardeio propagandístico em relaçào aos métodos didáticos com os quais deveria ser tratado o suposto autismo de seu filho um menino muito bonito, a quem so- mente um ollos experimentado em diagnóstico diferencial atribuiria problemas neurológicos - encontrou, depois de algumas entrevistas comigo, as palavras precisas para enunciar suas novas conclusoes: "Claro!" - disse - "Trata-se de sermos pais normais!"

Se um analista tivesse partido da, suposiçào de que os graves problemas na constituiçà) do sujeito que afetavam () menino haviam se originado a partir da realizaçào das fantasias inconscientes clos pais, o pai nào haveria tido a possibilidade de chegar à conclusào que chegou, e também nào teria sido possivel seu necessário reposicionamento no lugar de "pai normal". No outro extremo, supor que tudo se deve a questòess orgânicas é desconhecer o efeito da desorientaçào e do desencontro surgido diante das respostas da criança, assim como os efeitos de sua ampliaçào angustiante a partir do diagnóstico, juntamente com o tipo de propostas de tratamento que estào em voga. Em relação ao destino da criança, a oferta de um caminho subjetivamente normalizado na ordem humana é a única possibilidade para que continue construindo e desenvolvendo as condiçòes que efetivamente poderiam permitir-lhe apropriar-se de seus passos.

Já falamos das causas, mas, o que dizer de tyche? Creio que nada representa melhor o encontro com o real que o instante em que uma màe olha e vê, pela primeira vez o corpinho real do bebê que saiu de suas entranhas, esse que vem ocupar o lugar que até esse momento ocupou o objeto imaginado. Encontros e desencontros, grandes ou pequenos, com um plus a mais ou um plus a menos, sempre é desencontro e sempre há encontro.

O inconsciente não (rế no acaso e menos ainda no acaso de um acidente biológico. "Como o Outro nào existe, nào me resta outra alternativa que 
assumir a culpa sobre o eu" (Lacan, 1985b, P. 800), dizem os pais, lamentando-se. É paradoxal que as conceituações de alguns analistas retifiquem que a culpa - ou a causa - deve-se exclusivamente ao fantasma dos pais - pais machucados eles mesmos pela alteração em sua descendência.

Mas nào é verdade que a sorte chegue sempre vestida de má sorte.

E como eu prefiro os finais felizes - que também existem - concluo com a última estrofe da mesma canção de Silvio Rodriguez, que diz o seguinte:

"Cuando Juan regresaba a su

lecho, no sabia,

oh, alma querida!, que en la noche

lluviosa y sin techo,

lo esperaba el amor de su vida" 3 .

\section{REFERENNCIAS BIBLIOGRÁFICAS}

CORIAT, E. (1997). Psicanálise e clinica de behês. Porto Alegre. Artes e Ofícios.

FREUD), S. (1973a). Carta 52. In: Obras Completas. Madrid. Biblioteca Nueva. [1896].

FREUD, S. (1973h). La Dinámica de la transferência. In: Obras Completas. Madrid. Biblioteca Nueva. [1912].

FREUID, S. (19730). Lo siniestro. In: Obras Completas. Madrid. Biblioteca Nueva. [1919].

LACAN, J. (1973). Seminario XI: LOS cuatro conceptos fundamentales del psicoanálisis. Buenos Aires. Paidós.

LACAN, J. (1985a). Posición del inconsciente. In: Escritos 2. Buenos Aires. Siglo Veintiuno.

LACAN, J. (1985h). Subversión del sujeto y dialéctica del deseo en el insconsciente freudiano (1960). In: Liscritos 2. Buenos Aires, Siglo Veintiuno.

LACAN, J. (1986). Seminario III: Las Psicosis (1955-56). Espanha. Paidós.

\section{NOTAS}

(1) Trahaiho apresentado na Reuniào Lacanoamericana de Psicanálise da Bahia, realizada de 27 a 30 de agosto de 1997.

(2) N.T.: "Quando Pedro abriu sua jancla, nào sabia, meu amor, nào sabibia, que a luz desta clara manhà, era a luz de seu último dia. F as causas foram se aproximando, cotidianas, invisíveis, e o acaso foi envolvendo-o, poderoso, irivencível".

(3) N.T.: "Quando Juan regressava a seu leito, nào sabia, oh, alma queridat, que na noite chuvosa e sem teto, esperava-o o) amor de sua vida." 